\title{
Influencias extranjeras, miradas locales. La televisión pública en Uruguay (1963- 1968)
}

Florencia Soria

Universidad de la República

Recibido: 10/11/2016

Aceptado: 02/12/2016

\section{Resumen}

El artículo propone describir y analizar la reglamentación y las posiciones discursivas de actores políticos, autoridades del Servicio Oficial de Difusión Radio Eléctrica (SODRE) y empresarios de los medios de comunicación sobre la televisión pública en Uruguay entre 1963 y 1968. Desde la historia cultural y la sociología de la cultura, el artículo se centra en dos hipótesis: a) la autorización que el SODRE otorgó al Canal 5 para vender publicidad comercial motivó la primera discusión política sobre la televisión pública como institución social; b) esta discusión puso en juego un intrincado diálogo entre modelos y políticas de comunicación en el marco de los intensos debates y proyectos sobre los modos de resolver la crisis del país y en el contexto internacional de la Guerra Fría.

Palabras clave: televisión pública en Uruguay, historia de los medios, historia de la comunicación, políticas de comunicación.

\section{Foreign influences, local perspectives. Public Television in Uruguay (1963- 1968)}

\begin{abstract}
The article proposes to describe and analyze the regulation and discursive positions of political actors, Official Radio Broadcasting Service Electric (SODRE)'s authorities and businessmen of the media about public television in Uruguay between 1963 and 1968. From the cultural history and sociology of culture, the article focuses on two assumptions: a) the authorization granted to the SODRE Channel 5 to sell
\end{abstract}


commercial advertising led to the first political discussion about public television as a social institution; b) this discussion involved an intricate dialogue between models and communication policies in the frame of intensive discussions and projects on ways to resolve the crisis in the country and in the international context of the Cold War

Keywords: public television in Uruguay, media history, history of communication, communication policies.

\section{Introducción}

El estudio de la historia de los medios es un difuso campo que conjuga, por lo menos, los aportes de la Historia y la Comunicación. En Uruguay, la historiografía ha realizado importantes avances en el estudio del pasado de la radio, el cine y la prensa. Sin embargo, los antecedentes de la historia de la televisión oscilan entre escasas investigaciones académicas ${ }^{1}$ y un conjunto de obras abocadas a la recopilación de anécdotas y testimonios de experiencias ante el nuevo medio ${ }^{2}$. Desde la Comunicación, numerosas investigaciones han estudiado la televisión en Uruguay fundamentalmente desde la economía política de la comunicación-, pero enfocándose en el período contemporáneo.

Desde la perspectiva de Raymond Williams, el artículo3 busca analizar el proceso de institucionalización de la televisión como tecnología, lo que implica atender a su carácter eminentemente social, es decir, considerar que "está

\footnotetext{
${ }^{1}$ El trabajo de Carlos García Rubio (GARCÍA RUBIO, Carlos (ed.), Televisión estatal ¿qué hacer con ella?, Montevideo, Universidad Católica del Uruguay, 1998) es un importante antecedente en la comprensión del desarrollo institucional de la televisión pública en Uruguay, al igual que la obra de Roque Faraone (FARAONE, Roque, Televisión y Estado, Montevideo, Cal y Canto, 1998; FARAONE, Roque, Estado y T.V. en el Uruguay, Montevideo, Fundación de Cultura Universitaria, 1989; FARAONE, Roque, Medios masivos de comunicación, Montevideo, Colección Nuestra Tierra, 1969) donde analiza la historia normativa e institucional de la televisión pública y comercial. Los estudios de Antonio Pereira (PEREIRA, Antonio, "Televisión y Dictadura en el Uruguay: cambios y permanencias", en ReHiMe. Cuadernos de la Red de Historia de los Medios, Prometeo, Buenos Aires, 2012, pp. 140-179) y trabajos posteriores de García Rubio, abordan la temática en otro período histórico al propuesto aquí, pero dan cuenta de una creciente preocupación desde la historia por analizar el pasado de los medios, sin considerarlos mera fuentes primarias.

2 BECEIRO, Ildefonso, La radio y la TV de los pioneros, Montevideo, Banda Oriental, 1994; PRATS, Luis, Ayer te vi. Crónica de la televisión uruguaya, Montevideo, Ediciones de la Banda Oriental, 2009.

3 El artículo presenta algunos avances iniciales de una investigación -aún un curso- desarrollada para la tesis de Maestría en Comunicación y Cultura de la Universidad de Buenos Aires.
} 
necesariamente ligada, de forma compleja y variable, a otras relaciones e instituciones sociales" 4 y a la condiciones económicas y sociales ${ }^{5}$. Como sostiene Varela para el caso argentino, este proceso está vinculado al pasaje del "televisor" entendido como un aparato técnico, un electrodoméstico que es objeto de consumo y recepcionado-, a la "televisión", es decir, cuando la invención técnica pasa a tener una específica forma y función social. En este sentido, la "televisión" implica dejar de percibir al nuevo medio como una novedad tecnológica, para entenderlo como un agente cultural6.

De la complejidad y amplitud de este proceso, el artículo se limita a considerar algunos aspectos de la regulación normativa de la televisión pública, su implementación y debate, es decir, considera aspectos de la estructura institucional televisiva que hacen a su fase de producción7. Esto no significa que pretendamos buscar la "intención original" del desarrollo de esta tecnología como elemento determinante de su definición como institución social, en tanto otros grupos sociales desarrollan la tecnología con diversos propósitos y efectos. Como sostiene Williams, "la determinación es un proceso social real, pero nunca (...) un conjunto de causas completamente predecibles que controlan todo" 8 , aunque, sin embargo, fijan límites y ejercen presiones sobre las diversas prácticas sociales. En este sentido, las relaciones entre las determinaciones negativas y positivas en el proceso social en su totalidad, permiten comprender las tensiones entre las formaciones - y su relación con las instituciones formales- que mantienen el modo social y aquellas que presionan con demandas nuevas a concretar9. De aquí la necesidad de analizar el proceso de reglamentación y la forma de intervención de los actores políticos y empresas

\footnotetext{
4 WILLIAMS, Raymond, Televisión. Tecnología y forma cultural, Buenos Aires, Paidós, 2011, p. 185.

5 Recordemos que para el autor las instituciones y sus relaciones son un aspecto de la organización general en el marco de la cultura de una época entendida como "las relaciones entre los elementos de todo un modo de vida" (WILLIAMS, Raymond, La larga revolución, Buenos Aires, Nueva Visión, 2009, p. 56). Desde esta perspectiva, la historia cultural para Williams debe analizar las relaciones entre las historias particulares buscando comprender la forma de la organización general en un momento. Pero esta totalidad no es plenamente aprehensible porque no es posible recuperar las relaciones entre las actividades específicas y los modos de pensar y vivir. Sin embargo, el análisis de la cultura -en su sentido documental-, nos provee de pruebas que expresan aspectos de la vida real que hacen a la organización total y nos permiten acercarnos a ella.

6 VARELA, Mirta, "Del televisor a la televisión: La incorporación de la TV en la Argentina", Causas y Azares. Los lenguajes de la comunicación y la cultura en (la) crisis. Buenos Aires, año III, ${ }^{\circ} 4,1996$, pp. 107-115; VARELA, Mirta, La televisión criolla, Buenos Aires, Edhasa, 2005.

7 HALL, Stuart, "Codificación y decodificación de el discurso televisivo", Cuadernos de Información y Comunicación, $\mathrm{n}^{\circ} 9$, 2004, pp. 210- 236.

8 WILLIAMS, Raymond, Televisión...., ob. cit., p. 166.

9 WILLIAMS, Raymond, Marxismo y literatura, Barcelona, Península, 2000.
} 
comerciales en el proceso de institucionalización social de la televisión pública así como los proyectos truncos y discrepancias respecto a la orientación que debían seguir las normativas -particularmente la autorización brindada a la radio y televisión del SODRE para vender publicidad comercial-. El artículo busca aportar en la comprensión de estas diferencias en las concepciones del rumbo y modelo que debían seguir las políticas culturales y comunicacionales del país como aspectos de las transformaciones profundas del Uruguay de la década de los sesenta y en el contexto internacional de la Guerra Fría.

Con este objetivo, el trabajo se estructura en tres grandes secciones: en primer lugar, examinaremos los antecedentes normativos al surgimiento de la televisión pública, es decir, la reglamentación para la creación del SODRE y la regulación de la radiodifusión buscando comprender las líneas de continuidad y divergencia entre la radio y la televisión. En segundo lugar, abordaremos el proceso de creación del canal público considerando la legislación vigente y dos proyectos de ley que no fueron aprobados pero que dan cuenta de las divergencias existentes. En tercer lugar, analizaremos el enfrentamiento entre la Asociación Nacional de Broadcasters Uruguayos (ANDEBU) y el SODRE en el debate parlamentario de 1966 y 1967, intentando comprender cómo se enfrentaban los modelos de comunicación que defendían los distintos sectores políticos, en diálogo con las propuestas de ANDEBU y los proyectos del SODRE.

Desde el punto de vista metodológico, el trabajo implicó un análisis de contenido a partir del relevamiento, procesamiento y estudio heurístico de diversas fuentes primarias: los Diarios de sesiones de las cámaras de senadores y diputados entre 1963 y 1968, los Diarios de sesiones de la Asamblea General entre 1950 y 1963 , publicaciones de ANDEBU -en especial, "Memorandum 67" y "Una ofensiva contra la radio y la televisión"-, la publicación "Sodre. Su derecho a publicidad. Su misión Educacional. La defensa de la soberanía”. Se consultó el fondo del Ministerio de Instrucción Pública del Archivo General de la Nación, así como diversas normativas durante el período. Finalmente, utilizamos documentación del archivo personal del primer director del canal, Justino Zavala Carvalho ${ }^{10}$.

\footnotetext{
10 Agradecemos a la familia de Justino Zavala Carvalho por permitirnos el acceso al material que se encuentra su posesión.
} 
La delimitación cronológica comienza con la inauguración del Canal 5 del SODRE en 1963 y finaliza con la separación del cargo de su director, Zavala Carvalho, lo que marca el fin de una etapa del proyecto comunicacional de la televisión pública y el inicio de un proceso de debilitamiento institucional del SODRE en el período previo al golpe de Estado de 1973. En este sentido, la periodización busca alejarse de la cronología de la historia política proponiendo etapas propias de la historia de los medios.

\section{Antecedentes}

La primera vez que el Estado Uruguayo manifestó su interés por crear un servicio público de televisión fue en 1936 con la ampliación de la Ley de creación del SODRE ${ }^{11}$, con lo cual, se inscribió al nuevo medio en un marco institucional cuya finalidad era "la perifonía de programas culturales e informativos" ${ }^{12}$. Con este objetivo, desde su creación en 1929 el SODRE había desarrollado un conjunto de cuerpos estables ${ }^{13}$, creó la Discoteca Nacional -en 1929- y la radio pública CX6 SODRE -en 1930-, que ampliaba los cometidos de la institución al ámbito de la radiodifusión.

De Torres sostiene que la radio pública pudo cumplir efectivamente los ambiguos objetivos del SODRE -transmitir información y cultura-, gracias a la forma de gobierno de la institución -a través de una Comisión Directiva integrada por actores vinculados a la cultura y la educación-, su autonomía económica, un "diseño institucional de doble vía"14 - es decir, mediante el vínculo de la radio pública y la Discoteca con las actividades del Estudio Auditorio-, el capital en recursos humanos que existía en el país y la formación del público, entre otros factores. CX6 SODRE quedó inscripta en una "política cultural integral del Estado"15 heredera de la tradición cultural y política del Uruguay de los años veinte y treinta. La radio pública

\footnotetext{
${ }_{11}$ En ella se establecía que uno de los objetivos de la institución era "adquirir, construir, instalar, conservar, ampliar, mejorar, organizar o explorar estaciones, equipos, laboratorios, talleres, fábricas, almacenes y estudios de polifonía, televisión, cinematografía y fonografía” (Registro Nacional Leyes y Decretos (en adelante RNLyD), 30 de diciembre de 1936, p. 997)

12 SERVICIO OFICIAL DE DIFUSIÓN RADIO ELÉCTRICA, Su organización y cometidos. Memoria de la labor realizada entre 1930-1962, Montevideo, SODRE, 1936, p. 29.

13 En 1931 nació la Orquesta Sinfónica (OSSODRE) y el Conjunto de Música de Cámara, en 1934 fue creado el Coro y un año después, el Ballet.

14 DE TORRES, Inés, "El surgimiento de la radiodifusión pública en Hispanoamérica. Contextos, modelos y el estudio de un caso singular: el SODRE, la radio pública estatal de Uruguay (1929)", Revista internacional de Historia de la Comunicación, $\mathrm{N}^{\mathrm{0}} 5$, Vol.1, año 2015, p. 131.

${ }_{15}$ DE TORRES, Inés, ob. cit., p. 138
} 
nació respaldada por una fuerte inversión económica y "una previsión para su futuro desarrollo ubicándose entre las mejores y más potentes del país"16. Su emplazamiento inicial en el Palacio Legislativo "le otorgaba a esta estación un lugar muy destacado, de primer orden asociado el mayor símbolo de la República"17.

CX6 SODRE se insertó en un marco de paulatino crecimiento de la cantidad de radiodifusoras -de dos estaciones en 1922-1923 se pasa a 14 en 19318 ${ }^{18}$. La regulación que definió la radiofonía comercial y pública se plasmó en la Ley $\mathrm{N}^{\circ} 8.390$ que mantenía el ejercicio privado pero daba preferencia a las ondas radiofónicas del Estado en cuanto al horario, longitud de onda y funcionamiento. Las licencias para el ejercicio comercial de la radiofonía eran otorgadas por la Dirección de los Servicios de Radiocomunicaciones que podía suspender una transmisión o multarla si no tenía autorización, interfería con las estaciones del Estado, transmitía fuera del horario oficial de su funcionamiento o emitía "comunicaciones maliciosas o inmorales que afecten las buenas costumbre y el buen nombre del progreso de las radiodifusiones" 19 . Durante todo el período que analizamos, los once breves artículos de esta Ley fueron el marco general para el ejercicio de la radio y televisión y para definir las relaciones entre los medios públicos y privados. Según Maronna ${ }^{20}$, la aprobación de la Ley implicó un escueto debate parlamentario sobre la relación de las ondas radiotelegráficas del Estado y las empresas comerciales y la institucionalidad a la que debía inscribirse la radiofonía pública -lo que implicó su pasaje del Ministerio de Guerra y Marina al Ministerio de Instrucción Pública-

\section{El proceso de creación del Canal 5}

Así como la radio pública había sido celebrada en su comienzo, la fecha elegida para la inauguración del Canal 5 del SODRE coincidió con el natalicio de José Artigas vinculando simbólicamente al nuevo medio con la identidad nacional ${ }^{21}$. Al igual que

\footnotetext{
16 MARONNA, Mónica, La radio en busca de oyentes. Historia social y cultural de la radiofonía en Montevideo (1922-1939), [tesis de Doctorado inédita], Buenos Aires, 2016, p. 132

17. MARONNA, Mónica, ob. cit., p. 132

${ }^{18}$ MARONNA, Mónica, "La radio montevideana en busca de oyentes", Cuadernos del Claeh, año 33, n 100 ( $2^{\mathrm{a}}$ serie), 2012.

19 RNLyD, 13 de noviembre de 1928, p. 842.

${ }^{20}$ MARONNA, Mónica, La radio en busca de oyentes..., ob. cit.

${ }^{21}$ Varela analiza cómo las ceremonias inaugurales de la televisión en América Latina están vinculadas a la construcción de la identidad nacional - algo semejante ocurrió en otros países como Alemania, Estados Unidos, España o Gran Bretaña-. Esta relación se manifestaba con la presencia del presidente en la ceremonia y con la fecha elegida para dar comienzo a las transmisiones, simbólicamente ligadas a
} 
la radio, la televisión nació regulada por la Ley de 1928 aunque hubo una serie de normativas que la complementaron ${ }^{22}$ buscando: reafirmar el carácter precario y revocable en cualquier momento de las licencias que otorgaba el Estado a las radiodifusoras -ante algunos reclamos de ANDEBU-, definir la radiodifusión como servicio público ${ }^{23}$ y, sobre esta base, prohibir a las empresas hacer negocios con el uso de la onda. Además, se buscó establecer obligaciones sobre los prestadores de servicios radiofónicos privados: en 1945 se estableció que "sus transmisiones serán esencialmente de carácter cultural, instructivo, científico, artístico"24. En 1956 las "Normas provisorias jurídico administrativas para la explotación de estaciones de televisión” 25 - cuyo carácter provisorio no fue revisado durante la década de los sesenta-, establecieron que los permisos de las licencias durarían cinco años, no podían ser transferidos, debían estar a nombre de ciudadanos uruguayos, contar con ciertas bases económicas y los contenidos de la televisión no podían lesionar las relaciones internacionales, ni la moral y buenas costumbres. Sin embargo, como constata Faraone ${ }^{26}$, estas obligaciones no fueron aplicadas.

La expresión de voluntad del Estado por crear una televisión pública en 1936 antecedía el nacimiento de la televisión en el país ${ }^{27}$, sin embargo, debido al largo proceso de su implementación recién pudo materializarse en 1963. Entre 1950 y 1961, un conjunto de normativas nacionales y departamentales destinaron fondos para el

la Nación - como en los casos de México, Cuba o Argentina-. (VARELA, Mirta, "Televisión pública en América Latina: instrumento político, experimento estético, audiencia nacional”, en GUERIN, Ana Isabel y otros (comp.), Pensar la televisión pública, Buenos Aires, La Crujía, 2013).

${ }_{22}$ Fundamentalmente, los decretos $\mathrm{N}^{\circ} 3274$ y $\mathrm{N}^{\circ} 3229$ del 9 de junio y del 3 de noviembre de $1944-$ respectivamente-, el decreto $\mathrm{N}^{\circ} 448$ del 4 de marzo de 1945, el decreto $\mathrm{N}^{\circ} 23.949$ del 7 de junio de 1956 y la resolución del Ministerio de Defensa 1401|964 de 1964.

${ }^{23}$ La discusión sobre la relación de los medios de comunicación públicos y privados tanto en Europa como en Estados Unidos, implicó un debate sobre el sentido de "servicio público" y las implicaciones de una regulación orientada hacia el "interés público" (VAN CUILENBURG, Jan y MCQUAIL, Denis, "Cambios en el Paradigma de Política de Medios. Hacia un nuevo paradigma de políticas de comunicación”, European Journal of Communication, vol 18, $\mathrm{n}^{0}$ 2, Sage, Londres, pp. 181-207. [Traducción a cargo del equipo conformado por Mariela Baladrón, Ana Bizberge, Marianela Del Giúdice, Cecilia Fariña, Jorgelina Rojo, Magdalena Restovich, Bernadette Califano y Guillermo Mastrini. Disponible en Internet: http://mbecerra.blog.unq.edu.ar/modules/docmanager/index.php?curent dir=12(Consultado el 20 de abril de 2016)]). Estas definiciones integraron parte de la reglamentación, discusión parlamentaria y conflictividad con ANDEBU, como mencionaremos más adelante. Por su complejidad y extensión no es posible abordarlo aquí pero será un aspecto de futuras investigaciones.

24 RNLyD, 8 de marzo de 1945, p. 214.

25 MINISTERIO DE DEFENSA, Normas provisorias jurídico administrativas para la explotación de estaciones de televisión, Montevideo, Imprenta militar, 1956, p.1.

${ }^{26}$ FARAONE, Roque, Televisión y Estado, ob. cit., p. 15

${ }^{27}$ El primer Canal de televisión, Saeta- Canal 10, comenzó en 1956, seguido por Monte Carlo- Canal 4 en 1961 y Teledoce- Canal 12 en 1962. 
inicio de la instalación de la televisión pública, definieron el predio para su construcción edilicia y permitieron la adquisición de los equipos necesarios, mediante una licitación pública que se saldó con la adjudicación a General Electric S.A. en 1954. En 1955, la resolución No 16.657 del Consejo Nacional de Gobierno reservó para el SODRE el canal de televisión No 5 (76- $82 \mathrm{mg} / \mathrm{s}$. con la característica CXA T. V.-5) y los canales 3 y 8. En febrero de 1963 comenzó la emisión experimental con dos horas diarias y el 19 de junio del mismo año se iniciaron oficialmente las emisiones del canal.

El marco normativo que administró el ejercicio de la radio y televisión entre 1928 y 1966 tiene un carácter fundamentalmente técnico, lo que fue característico de los primeros años del ejercicio de la radiodifusión ${ }^{28}$. Sin embargo, esta primera etapa se había superado en muchos países del mundo hacia la década de los sesenta, cuando se desarrolló lo que Van Cuilenburg y McQuail denominaron "el paradigma de política de servicio público de los medios"29, "más caracterizado por consideraciones normativas y políticas que tecnológicas y por la búsqueda de una coherencia y estabilidad nacional" 30 .

Por otro lado, la reglamentación muestra una continuidad entre la radio y la televisión. Como sostiene Maronna ${ }^{31}$ para el caso uruguayo o Varela ${ }^{2}$ para la situación argentina, se pensaba la radio y televisión como una linealidad en el devenir de los inventos técnicos, lo que implicaba una indefinición del significado y usos sociales específicos de la nueva tecnología. Tal y como sostiene Willimas "la respuesta tecnológica a una necesidad [social], no es tanto una cuestión de la necesidad misma, sino del lugar que ocupa en una formación social existente" 33 y, en consecuencia, si los grupos que toman las decisiones entienden una necesidad social como prioritaria, efectivamente la tecnología podrá operar, "entendida como algo distinto de los artefactos técnicos disponibles". Siguiendo esta perspectiva, la reglamentación refleja una concepción de los grupos políticos más ligada al "televisor" que a la "televisión".

\footnotetext{
28 VAN CUILENBURG, Jan y MCQUAIL, Denis, ob. cit.; WILLIAMS, Raymond, Televisión...., ob. cit.; VARELA, Mirta, La televisión...ob. cit.

29 VAN CUILENBURG, Jan y MCQUAIL, Denis, ob. cit., p.1.

$3^{\circ}$ VAN CUILENBURG, Jan y MCQUAIL, Denis, ob. cit., p. 14.

${ }^{31}$ MARONNA, Mónica, "La radio montevideana..., ob cit.

$3^{2}$ VARELA, Mirta, La televisión...ob. cit.

33 WILLIAMS, Raymond, Televisión...., ob. cit., p. 32.
} 
La continuidad entre la radio y la televisión también se refleja en la inscripción de ambos medios públicos en la órbita del SODRE, con lo cual, quedaban inscriptos en esta política cultural. Desde este punto de vista, no parece posible afirmar plenamente que había una "ausencia de política pública"34 respecto al ejercicio de la televisión. Sin embargo, los rasgos normativos de la época y su aplicación no parecen definir claramente la relación entre los prestadores de servicios televisivos públicos y privados. Si entendemos las políticas públicas en comunicación, no solo como la definición de un objetivo, los medios para llevarlo a cabo y un cronograma, sino también como el reflejo del "trato hecho en un momento y lugar particular y el equilibrio de poder y ventajas entre el gobierno y la industria"35, la reglamentación parece mostrar una ambivalencia entre: una pretensión de dar preferencia a la radiodifusión oficial -definida en la Ley de 1928- y la precariedad económica que tuvo el canal público y las dificultades para su nacimiento; la búsqueda por regular el funcionamiento de la televisión privada y su incapacidad para llevarlo a la práctica; algunas intenciones de regular el ejercicio de la televisión pública y privada atendiendo a sus particularidades y funciones sociales y el estancamiento de estas propuestas -como veremos en el siguiente apartado-.

En este marco normativo, entre 1963 y 1966, hubo muy pocas alusiones en el parlamento a la televisión en general y, particularmente, a la televisión estatal. Su inauguración pasó inadvertida y las pocas referencias al tema durante este período recaen en la intervención puntual de algunos legisladores sin motivar un debate más general. Por ejemplo, en la Cámara de Representantes hubo alusiones a la situación contractual de los funcionarios del SODRE que pasaban a realizar tareas para la televisión, a las transmisiones experimentales en Fray Bentos o la incapacidad de emitir espectáculos deportivos en el canal por falta de equipos. En el Senado, Tomás Brena (Unión Cívica del Uruguay) advirtió en $1959^{36}$ sobre la necesidad de impulsar el proyecto de televisión pública postergado por trabas económicas y sociales. Los riesgos de quedar sin las señales adjudicadas al canal del SODRE por no hacer uso de ellas en los plazos establecidos internacionalmente y la necesidad de impulsar un servicio estatal de televisión que llegue a todo el país, son otros de los temas

34 FARAONE, Roque, Televisión y Estado, ob. cit., p. 17.

35 VAN CUILENBURG, Jan y MCQUAIL, Denis, ob. cit., p. 182.

${ }_{36}$ Diario de Sesiones Cámara de Senadores (en adelante DSCS), 6 de agosto de 1959, t. 226, pp. 324326 
abordados en esa sesión. En general había acuerdo en los legisladores uruguayos de los diferentes partidos sobre la necesidad de apresurar la instalación del canal del SODRE.

En la misma línea, el escribano Luis Alberto Viera envió en 1965 un escrito a la Cámara de Representantes a través del diputado colorado Julio César da Rosa, donde realizó un pedido poco fructífero:

"La obra que -bajo una Dirección consiente de la función social del imponente medio de comunicación de masas que es la TV- viene realizando y programa para el futuro del Canal 5, merece la inmediata atención de los Poderes Públicos. Pocas veces el Estado ha dispuesto de un instrumento tan poderoso y a la vez perfectible, como en estos instantes a través de la televisión”37

El pedido de Viera parece inscribirse en la tendencia de la región. Por ejemplo, en Argentina durante las dos presidencias de Perón (1946-1955) el gobierno utilizó la prensa, la radio, el cine y luego la televisión -desde 1951- con el objetivo de "construir identidades políticas, sociales y culturales para formar y organizar a la opinión pública" 38 . Con este fin, el peronismo creó la Ley de Radiodifusión - No 14.241/53que ya en 1953 definía una programación educativa, cultural, artística, informativa y de entretenimiento para el interés general, establecía los principios que regían la radiodifusión y regulaba el régimen de otorgamiento de licencias 39 .

En la misma línea, el Código Brasilero de Telecomunicaciones aprobó en 1962 la Ley $\mathrm{N}^{0}$ 4.117: una amplia normativa que definía el procedimiento para las adjudicaciones, las garantías para los concesionarios, sus posibles sanciones y creaba una institución encargada de regular el sistema llamada Consejo Nacional de Telecomunicaciones. Como en Argentina, las autoridades rápidamente vislumbraron la potencialidad de la televisión -junto a los otros medios masivos- para alcanzar fines políticos. Más aún con el régimen militar que vivió Brasil entre 1964 y 1985,

37 Diario de Sesiones de la Cámara de Representantes (en adelante DSCR), 25 de noviembre de 1965, t.537, p. 634 .

${ }^{38}$ MASTRINI, Guillermo (ed.), Mucho ruido, pocas leyes. Economía y políticas de comunicación en la Argentina, Buenos Aires, La crujía, 2009, p. 78.

39 Sin dudas, a pesar que Argentina reguló los medios antes que Uruguay, las medidas peronistas atentaron contra la libertad de expresión y tampoco hubo un proyecto estatal de radiodifusión que continuara tras el derrocamiento de Perón y la posterior consolidación de la televisión durante los años sesenta. Como observa Mastrini, "el Estado ha carecido de una política cultural, y mucho menos en medios públicos, coherente y se ha limitado a sancionar el marco regulatorio de la radiodifusión y un limitado control de contenidos políticos" (MASTRINI, Guillermo, ob. cit., p.106). 
donde "el financiamiento de los "medios masivos" fue un vehículo poderoso para su control estatal" 40 , debido a la relación del gobierno con los bancos, su manejo de las licencias y subsidios para la importación de materiales.

\section{Las excepciones a la regla}

Hubo dos intentos por definir otras formas de regular la televisión en su conjunto y la televisión pública en particular. El primero de ellos fue un anteproyecto de ley presentado en 1957 por la Comisión Directiva del SODRE al Poder Ejecutivo, que -tras algunas modificaciones- fue remitido al Parlamento. El objetivo del proyecto era generar "recursos tendientes a hacer posible la implementación por el SODRE de un servicio permanente y de alta jerarquía cultural, en materia de Televisión"41. Estos recursos estarían especialmente destinados a la "paulatina extensión a todo el territorio de la República, a través de una red nacional, del servicio de televisión, así como lo relativo a la construcción de un tele-radio-centro, de costo naturalmente elevado" 42 . En la fundamentación del anteproyecto que realizó la Comisión Directiva del SODRE, se justificaba el incremento económico destinado a la televisión pública por su

"doble importancia: la suya propia, independiente y basada en sus propios valores, y la de hacer rendir en una mayor proporción a los distintos elementos que ya actúan dentro de la órbita del SODRE. Las enormes posibilidades reconocidas universalmente a la televisión como elemento de información y de educación al alcance de los grandes sectores populares, podrían ser utilizados por el SODRE en la máxima medida posible” 43

Por lo tanto, el proyecto no solo consideraba a la televisión pública como un vía más de transmisión de la cultura que buscaba difundir el SODRE, sino con particularidades que le eran específicas. Desde esta perspectiva, la fundamentación del proyecto explicitaba las líneas generales de la programación para la televisión pública: televisar los espectáculos del Estudio Auditorio, difundir espectáculos musicales -sobre todo ópera, ballet y conciertos orquestales pequeños-, transmitir

40 MATTOS, Sergio, "Un perfil de la televisión brasilera: 40 años de historia (1950- 1990)", Comunicación y Sociedad, $\mathrm{n}^{\mathrm{O}}$ 16- 17, setiembre - abril, 1993, Universidad de Guadalajara, p.58.

${ }^{41}$ Expediente sobre la "fundamentación y orientación general del servicio de T.V. del SODRE" del proyecto que se elevaba a la Asamblea General, s/f, Archivo personal de Justino Zavala Carvalho, Uruguay (en adelante AJZC), p. 1

42 Expediente caratulado “Televisión”, Carpeta ${ }^{\circ}$ 2792, Caja 658, Archivo General de la Nación (en adelante AGN), Uruguay.

43 Expediente con la "Fundamentación y orientación general del servicio de T.V. del SODRE" del proyecto que se elevaba a la Asamblea General, s/f, AJZC, pp. 3-4. 
tele- teatros, noticias, actividades artísticas, deportivas y cine44. Finalmente, se buscaría generar contenido educativo a partir del trabajo conjunto con las instituciones de enseñanza.

El proyecto que remitió el Poder Ejecutivo al Parlamento también argumentaba la necesidad de aprobación de la Ley para cumplir efectivamente los cometidos del SODRE pero se redujeron las líneas de programación definidas en la redacción anterior a una enumeración de ejemplos. La propuesta de financiación del canal público incluía: 1.600.00o pesos anuales y una partida única de 1.300.00o para la etapa de instalación inicial del canal45; la creación de un impuesto mensual de teleradiodifusión que debían pagar todos los habitantes de casas destinadas a comercio, vivienda o industria, siendo proporcional al costo del alquiler46; la creación de un gravamen mensual, de carácter nacional, que recaería sobre aquellos que tuvieran un receptor de televisión -siendo proporcional a su valor-; un tercer impuesto debía ser pagado por los fabricantes nacionales o importadores de televisores y accesorios y era del quince por ciento del precio de venta o valor estimado sobre las ventas o transacciones; finalmente un cuarto tributo recaería en los vendedores o reparadores de televisores: abonarían el diez por ciento de la transacción o del servicio47.

Con este anteproyecto el SODRE definía una serie de objetivos específicos en relación a la televisión pública -inscritos en los fines generales de la instituciónatendiendo a las particularidades del medio de comunicación y estableciendo los mecanismos económicos e institucionales para alcanzarlos. Sin embargo, el proyecto ingresó a la Cámara de Representantes el 6 de agosto de 1957 y fue remitido a la Comisión de Presupuestos sin discusión.

\footnotetext{
44 La emisión de cine se basaría en el material que tenía Cine Arte y mediante la producción de contenido cinematográfico del SODRE. Para hacerlo, el proyecto proponía la incorporación de la División Fotocinematográfica radicada en el Ministerio de Instrucción Pública y Previsión Social.

45 Parte de este monto sería financiado por Rentas Generales y el resto por diferentes entres del estado a los que el SODRE retribuirá con propaganda.

${ }^{46} \mathrm{El}$ impuesto inicialmente era solo para Montevideo y luego se extendería al resto del país a medida que el SODRE lograra llegar a todo el territorio.

$47 \mathrm{El}$ proyecto también regulaba algunos aspectos en relación a los funcionarios que trabajaban en la televisión pública: se permitía su contratación en régimen de dedicación total, habilitaba la contratación de funcionarios de la administración pública hasta la aprobación del nuevo Presupuesto General de Sueldos y Gastos y por el plazo de un año y se regulaban las prestaciones de servicios que debían brindar las personas becadas por el SODRE para formarse en el extranjero sobre la televisión. Además, los espectáculos públicos que contaran con el apoyo del Estado podían ser televisados en forma libre por el SODRE.
} 
El segundo intento por redefinir la regulación sobre la televisión fue en 1963 cuando se presentó el proyecto de ley "Trabajo en la radio y en la televisión"48. La propuesta surgió ante los reclamos de la Sociedad Uruguaya de Actores y la Federación Uruguaya de Espectáculos Públicos por la exclusión de trabajadores uruguayos en la radio y televisión, ya sea por la contratación de extranjeros o por la utilización de video-tape. Aunque el proyecto -y sus antecesores- surgió para atender a esta demanda, la propuesta excedió la temática concreta y por eso consideramos relevante su atención. El proyecto definía la radio y la televisión como servicios públicos que debían garantizar la libertad de expresión, recepción y réplica así como el derecho a la información. Como servicios públicos deberían perseguir los siguientes objetivos:

"contribuir a fortalecer la integración nacional y a consolidar el respeto a los principios de la dignidad humana, la moral social y la institución familia, para erradicar las influencias nocivas y perturbadoras que inhiben o deforman el armónico desarrollo de la niñez y la juventud, exaltando los auténticos valores que conforman el patrimonio histórico, cultural, artístico e ideológico de la nación, difundiendo el acervo tradicional y la producción intelectual del país, afirmando las convicciones democráticas, la unidad nacional, y la elevación del nivel cultural del pueblo. Asimismo deberá contribuir a mejorar las formas de convivencia humanas, promoviendo la paz, la cooperación internacional, el intercambio y acercamiento cultural" 49

Para alcanzar tales metas el proyecto estableció claros lineamientos en la programación de la radio y la televisión: un setenta por ciento de las emisiones en todo el país debían ser en vivo -aunque podían incluirse también algunas grabaciones realizadas en Uruguay- y "este porcentaje debe estar formado en su totalidad con la intervención directa en la salida al aire con trabajadores uruguayos" 50 . Además, la programación trimestral de la radio y televisión debían

\footnotetext{
${ }^{8}$ Anteceden a este proyecto dos propuestas anteriores que parecen integrarse en él. Aunque ambos tienen diferencias considerables entre sí y respecto a la propuesta final, consideramos que, en términos generales, ambas están conjugadas en el proyecto que aquí analizamos. En efecto, varios de los representantes de las propuestas anteriores firmaron este proyecto. El primer antecedente fue la propuesta presentada el 2 de octubre de 1962 titulada "Programas de televisión. Integración con un $70 \%$ de personal uruguayo". La segunda, "Televisión. Intervención de trabajadores uruguayos" fue presentada el 12 de junio de 1963.

49 DSCR, 6 de agosto de 1963, t. 558, p. 270

5o DSCR, 6 de agosto de 1963, t. 558, p. 270. Para profesionalizar el trabajo nacional en radio y televisión y permitir el efectivo cumplimiento de estas disposiciones se crearía la Escuela de Actividades Profesionales Específicas para Radio y Televisión en la Universidad del Trabajo. Este título o su revalidación de conocimiento mediante exámenes en la Escuela, serían los únicos que oficialmente facultaban el ejercicio de las actividades en radio y televisión.
} 
incluir al menos un diez por ciento de programación docente, realizada por profesionales o "idóneos en la materia". En los hechos, esta normativa implicaba una fuerte preponderancia de la producción nacional sobre la extranjera -uno de los objetivos que persigue el proyecto, tal como se explicita en la exposición de motivos-. Incluso las películas, grabaciones artísticas y comerciales que no fueran nacionales enmarcadas en el treinta por ciento restantes de la programación- debían ser traducidas al castellano por trabajadores, atendiendo al porcentaje antes mencionado. Tampoco se podían emitir películas que no hayan sido realizadas para televisión, exceptuando las que transmitía el SODRE a partir del Cine Arte.

El material grabado en el extranjero emitido por la radio y televisión, además de los gravámenes que ya tenían por su importación, sumaría un recargo del veinte por ciento sobre el precio de producción. De lo recaudado se destinaría un setenta por ciento al SODRE -para fomentar en sus emisiones televisivas la participación de artistas uruguayos- y el restante, sería destinado a la financiación de la Comisión Nacional de Radio y Televisión que creaba la Ley. Esta Comisión sería la responsable de dar cumplimiento a todas las disposiciones previstas y estaría integrada por un representante del Poder Ejecutivo que la presidirá, dos delegados de los concesionarios de las ondas y dos de los trabajadores.

Los proyectos presentados en 1957 y 1963 parecen dar cuenta de una búsqueda por regular la televisión pública y comercial de forma alternativa a la tendencia normativa vigente hasta entonces. En el primer proyecto se definían las funciones específicas de la televisión pública y, en el segundo, los objetivos de toda la televisión. En ambos se pretendía generar fondos económicos para el cumplimiento de los fines de la televisión estatal, lo que afectaba directamente el ejercicio de las empresas privadas vinculadas a la televisión comercial y a la venta y distribución del aparato técnico. En el proyecto de 1963, establecidos los fines de toda la teledifusión, era posible instituir obligaciones sobre los prestadores de servicio privados, particularmente en relación a los contenidos. Si toda la normativa vigente definía a la televisión como un sistema concebido "para la transmisión y recepción, como procesos abstractos, con muy poca o ninguna definición de un contenido previo" 51 , el proyecto de 1963 buscaba claramente avanzar hacia la generación de contenidos no

${ }^{51}$ WILLIAMS, Raymond, Televisión...., ob. cit., p. 39. 
parasitarios que fueran verdadera producción nacional y específica para el nuevo medio de comunicación.

La búsqueda por un camino alternativo se manifestó en la exposición de motivos del proyecto de Ley de 1963 donde se constataba que la reglamentación que regía a la radio y televisión en el país tenía un carácter técnico y que los decretos posteriores a la Ley de 1928, no modificaban el "carácter simplista" de la norma. Asimismo, se argumentó la aprobación del proyecto en la ausencia de una definición clara de la radiodifusión -la educación y cultura- y de los mecanismos punitivos para el cumplimento de la normativa. Por lo tanto, existía un "anacronismo de nuestra Legislación radial, en una época en que proliferan las radiodifusoras comerciales, languidece la radiodifusión oficial y se produce un explosivo desarrollo de la televisión nacional" 52 . Los proyectos muestran cómo la institucionalidad social de la televisión no estaba predeterminada por la tecnología, sino que fue el resultado de "un conjunto de decisiones sociales determinadas, tomadas en circunstancias particulares que luego fueron ratificadas de manera tan amplia, aunque quizás imperfectamente" lo que hace "difícil verlas como resultados (retrospectivamente) inevitables" 53 .

Más allá de la tendencia técnica y de continuidad que parece mostrar el marco regulatorio de la radiodifusión desde los treinta, es pertinente considerar que la televisión comercial y pública nació en una coyuntura muy diferente a la de su medio antecesor. El fracaso de los proyectos de ley de 1957 y 1963, con los reajustes económicos que implicaban, puede leerse también como (in)decisión tomada en el contexto de la crisis económica que afectaba al país desde mediados de los años cincuenta, la cual implicó una reconfiguración del vínculo internacional del país en los cambios del mercado mundial y, al mismo tiempo, daba cuenta del agotamiento del modelo económico neobatllista (1947-1958) que podría considerarse como el quiebre definitivo "de toda una construcción económica de larga duración” 54.

${ }^{52} \mathrm{DSCR},, 6$ de agosto de 1963, t. 558, p. 271

53 WILLIAMS, Raymond, Televisión...., ob. cit., p. 37.

54 CAETANO, Gerardo; RILLA, José, Historia contemporánea del Uruguay. De la colonia al Mercosur, Montevideo, Fin de siglo, 1995, p. 201. 


\section{Enfrentamiento con ANDEBU}

En diciembre de 1963 Zavala elevó al Director General de la Comisión Directiva del SODRE, Héctor Laborde, un informe de evaluación55 de los primeros seis meses de la televisión resaltando la precariedad económica que tenía el canal y cómo esta situación afectaba el cumplimiento de sus objetivos. Solo existía un estudio, prácticamente no había repuestos para los equipos, no se tenía video- tape ni equipos de exteriores o la cantidad necesaria de canales de cámara, cámaras, luces, micrófonos, booms o grabadoras. Esto llevaba a la imposibilidad de emitir dos programas consecutivos en vivo - no había forma de desmontar el estudio para prepara el siguiente- y se "rellenaba" con cortometrajes seleccionados por su duración y no por la coherencia o el sentido de la programación general del canal.

Esta precariedad económica intentó sortease con la Ley presupuestal de $1964^{56}$ que obligaba a los entes autónomos y servicios descentralizados a invertir un veinte por ciento de lo destinado a publicidad en el SODRE. Como explicaba Zavala57 la aplicación de esta Ley teóricamente implicaba una inversión para los medios de comunicación del SODRE de 3.500.000 pesos en 1965. Sin embargo, en los hechos, el aporte de los entes y servicios del Estado fue de 700.000 pesos. En 1966, de los 4.500.00o pesos que debía recibir el SODRE por la aplicación de esta Ley, obtuvo 1.250.00o pesos. Ante este escenario, en mayo de 1966 la Comisión Directiva del SODRE autorizó a sus medios de comunicación -la radio y la televisión- a vender publicidad comercial ${ }^{8}$. La medida generó la reacción contraria de ANDEBU y motivó un debate parlamentario sobre el tema entre los años 1966 y 1967 que incluyó reflexiones más amplias sobre la política en comunicación, las relaciones del sector privado y público o las funciones e institucionalidad de la televisión pública. La amplitud de todos estos aspectos no puede ser abordada aquí por lo cual nos limitaremos a señalar algunos rasgos puntuales del debate.

\footnotetext{
55 Informe presentado ante el Director General del SODRE, Héctor Laborde, 19 de diciembre de 1963, AJZC.

${ }^{6}$ RNLyD, 28 de diciembre de 1964, p. 1533 art. 66.

57 Informe general del Canal 5, 1967, AJZC. p.4.

${ }_{58}^{8} \mathrm{La}$ resolución se sostuvo en el aval jurídico del informe que presentó el doctor Jauregui, Asesor Letrado y el Asesor del Ministerio de Instrucción Pública y Previsión Social. En el mismo sentido se pronunció luego el Fiscal de Gobierno, doctor Varela Seré, cuando el tema pasó a su competencia tras el reclamo de ANDEBU, sosteniendo que la venta de publicidad podía realizarse porque el SODRE es un servicio descentralizado -lo cuál era, desde el punto de vista legal, lo que generaba discrepancias-
} 


\section{Entre los modelos foráneos y las miradas locales}

La autorización a la venta de publicidad comercial del SODRE motivó una discusión sobre las relaciones entre las empresas públicas y privadas de comunicación y el rol que debía adoptar el Estado, ya sea como regulador -más o menos moderado- de un libre mercado en competencia o ejerciendo un rol monopólico de los medios de comunicación. Desde el sector herrerista del Partido Nacional, el senador Ángel María Gianola sostuvo que la venta de publicidad del SODRE generaría una "competencia desleal" porque su actividad estaba "exenta de impuestos y tributos locales" 59 . Por esta razón, solicitó un pedido de informes al Ministerio de Instrucción Pública y Previsión Social sobre las bases legales que sostuvieron la medida y el procedimiento de venta de publicidad. Argumentó su pedido manifestando que:

\footnotetext{
"a nuestro juicio, no es bastante el argumento aludido [la necesidad de obtener recursos económicos para mantener la emisión televisiva] para que el SODRE, desnaturalizando su función específica, de orden cultural y educacional, se lanze [sic] a una campaña publicitaria con firmas privadas, compitiendo con ventajas en un reducido mercado publicitario, como es el nuestro, con las emisoras radiofónicas y canales de televisión particulares" 60 .
}

La posición de ANDEBU se inscribió en la misma línea. En 1966, los Canales privados 10, 4 y 12, emitieron en sus pantallas la frase "La publicidad que propala el SODRE es ilegal, inconstitucional e inconveniente" 61 y en 1967, la Asociación publicó un extenso documento, el "Memorandum 67", donde se referían a "la campaña publicitaria que debieron desarrollar cuando la radiodifusión oficial comenzó su competencia desigual con las emisoras privadas en el campo de la publicidad comercial"62.

Por lo tanto, uno de los argumentos opositores a la venta de publicidad comercial de la televisión del SODRE, se sostenía en la potencial afección económica que implicaría sobre las empresas privadas y en la defensa de un modelo de comunicación liberal. En esta perspectiva parecen confluir las posiciones de

\footnotetext{
59 DSCS 8 de mayo de 1966, t. 252, p. 344.

60 DSCS, 8 de mayo de 1966, t. 252, p. 344.

${ }^{61}$ GARCÍA RUBIO, Carlos (ed.), Televisión estatal...ob. cit., p. 24.

62 ANDEBU, Memorandum 67, Montevideo, ANDEBU, 1967, p. 21.
} 
ANDEBU y el Herrerismo ${ }^{63}$, aún cuando divergen en otros aspectos de la discusión. Aunque no constatamos el ejercicio de un lobby político en el sentido estricto del término -reuniones reservadas o sobornos-, podemos definir, al menos, ciertas similitudes en su posición ideológica ${ }^{64}$. En este sentido, cabe destacar que el Partido Nacional - desde que ganó en 1958- llevó adelante una política económica con una fuerte orientación liberal, expresada en la Ley de Reforma Monetaria y Cambiaria y en la firma de la primera Carta de Intención con el Fondo Monetario Internacional65. Por otra parte, ya desde la década de los treinta y en el marco de la débil regulación que regía a los medios, se generó "un sistema que promovió el acercamiento y vínculo político como mecanismo para obtener o mantener una onda"66. Desde entonces, ANDEBU se había transformado en un grupo de presión política.

63 Sin dudas, es sumamente complejo definir el término "herrerismo" como una categoría relativamente homogénea. Desde fines de la década de los cincuenta y durante los sesenta el Partido Nacional vivió importantes transformaciones. Si la alianza herrero- ruralista - que llevó al Partido Nacional a la presidencia en las elecciones de 1958-, implicó la escisión de algunos componentes del viejo Herrismo en la Unión Blanca Democrática (UBD), opuesta al acuerdo ruralista, las diferencias entre Herrera y Benito Nardone y la muerte de Luis Alberto de Herrera en 1959, acentuaron la inestabilidad del Partido y sus sectores (ALONSO ELOY, Rosa; DEMASI, Carlos, Uruguay 1958- 1968. Crisis e estancamiento, Montevideo, Banda Oriental, 1986). En efecto, en las elecciones 1962, la mayoría de los votos correspondió el lema UBD, aliada con el grupo "ortodoxo" herrerista impulsado por Eduardo Víctor Haedo, aunque se dividieron antes de asumir el mandato ante la definición de los cargos que conformarían el Consejo Nacional de Gobierno. La tensión entre las filas blancas, se acentuó con la muerte de Nardone y Daniel Fernández Crespo en 1964 que reforzó la desorganización del partido y la dispersión política al no contar con figuras carismáticas que tomaran el lugar de los viejos líderes. A su vez, el ubedismo se resquebrajó entre miembros que se alejaron hacia el herrerismo y otros que pasaron a integrar el naciente "Movimiento Nacional de Rocha". La reforma constitucional de 1966 escindió aún más a las agrupaciones conforme apoyaron la propuesta elaborada entre diferentes componentes del Partido Nacional y Colorado o reaccionaron como anti-acuerdistas. A pesar de estas transformaciones creemos posible encontrar una posición concordante entre legisladores herrero- ruralistas y herreristas a favor de la reforma constitucional respecto al tema que aquí analizamos.

${ }^{64}$ Como sostiene Freedman, "una campaña de lobby exitosa, no sólo reside en los recursos y influencia política, sino también en un sentido de que la cuestión conecte con la amplia postura ideológica de quienes están en posiciones clave dentro del proceso de elaboración de políticas" (FREEDMAN, Des, "Las dinámicas del poder en la elaboración de políticas de medios en la actualidad", Media, Culture \& Society, v.26, $\mathrm{n}^{\circ}$ 6, noviembre 2006, Londres [Traducción realizada por el equipo de cátedra de "Políticas y planificación de la comunicación", de la Facultad de Ciencias Sociales, UBA. Disponible en Internet: http://politicasyplanificacion.sociales.uba.ar/files/2014/o7/freedman.pdf (Consultado el 20 de abril de 2016)], p. 15.)

${ }_{65}$ Aun cuando la propuesta económica del gobierno haya encontrado obstáculos en los "viejos factores estructurales de la sociedad uruguaya" (CAETANO, Gerardo; RILLA, José, ob. cit., p. 210-211) para su pleno desarrollo, podría considerarse un indicio de una perspectiva ideológica semejante con ANDEBU en materia económica. Por otra parte, aunque el segundo gobierno blanco electo en 1962 fue más tenue en su propuesta económica liberal, hay que considerar que la UBD había triunfado sobre la fracción herrero- ruralista. Además, hacia el final de este gobierno, se volvió a la ortodoxia fondomonetarista en materia económica.

${ }^{66}$ MARONNA, Mónica, La radio en busca de oyentes..., ob. cit., p. 3. 
Como parte de la tradicional retórica de las empresas comerciales de los medios de comunicación en otras partes del mundo, la defensa de un mercado liberado para ANDEBU estaba unida a la libertad de expresión. Así, reivindicaba "la radiodifusión americana predominantemente privada, actuando cómo área reservada a la libre expresión del pensamiento"67. En efecto, Estados Unidos tenía una larga tradición de fomento al ejercicio privado de la comunicación -ya desde el telégrafo y el teléfono-, aunque con regulaciones. Si bien hasta 1927 hubo una competencia comercial abierta entre las primeras cadenas de radiodifusión -que eran consorcios de fabricantes-, la Comisión Federal de Radio primero y la Comisión Federal de Comunicaciones después, regularon el otorgamiento de las licencias y definieron algunos mecanismos de contralor.

En contraposición a la perspectiva del Herrerismo y ANDEBU, casi toda el ala Batllista ${ }^{68}$ del Partido Colorado argumentó que la venta de publicidad del SODRE era la solución encontrada por la Institución para su supervivencia ante las dificultades económicas que atravesaba, aún cuando no fuera era el camino más deseable según

\begin{abstract}
${ }^{67}$ ANDEBU, ob. cit., p. 12.
$68 \mathrm{El} \mathrm{Battlismo} \mathrm{tampoco} \mathrm{fue} \mathrm{ajeno} \mathrm{a} \mathrm{las} \mathrm{transformaciones} \mathrm{y} \mathrm{escisiones.} \mathrm{Caetano} \mathrm{y} \mathrm{Rilla,} \mathrm{en} \mathrm{su} \mathrm{análisis}$ del gobierno de Luis Batlle Berres, se preguntan sobre los aspectos que unen y tensionan la diversidad de actores políticos que se proclaman sucesores de la tradición de José Batlle y Ordoñez. Luis Batlle Berres había salvaguardado -aunque con algunas diferencias, sobre todo su respecto a la democracia liberal- la herencia de su tío. Pero tras la derrota electoral de 1958, "el batllismo de los sesenta se enfrentó al desafío de una sociedad que comenzaba a vivir procesos radicales de cambio. Como era previsible, ante tan crítica circunstancia (que la muerte de Luis Batlle vino a agravar) el batllismo reeditó su dinámica de fraccionalización" (CAETANO, Gerardo; RILLA, José, ob. cit., p. 176). A la muerte de Luis Batlle Berres en 1964 -que acentuó el desdibujamiento de la unidad de la lista 15-, se sumó la escisión de Zelmar Michelini y la creación de la lista 99, con varios disconformes de la 15. Para las elecciones de 1966, encabezó la lista Jorge Batlle, con una propuesta que abandonada la tradición batllista y se acercaba a una concepción neoliberal en materia económica y social (FREGA, Ana y otros, Historia del Uruguay en el siglo XX (189o- 2005), Montevideo, Banda Oriental, 2010). Así, muchos disidentes se volcaron, no solo por la lista 99, sino también por el Frente Colorado de Unidad. En general, el partido acompañó la propuesta de reforma constitucional, que dará lugar a la nueva figura presidencial, Óscar Gestido.
\end{abstract}

Hacia 1966 parece definirse una concordancia entre la lista 14, 15 y los colorados contrarios a la reforma constitucional -como Amílcar Vasconsellos-, respecto a la venta de publicidad del SODRE. Sin embargo, hacia 1967 tanto Vasconsellos como Hierro Gambardella expresaron sus diferencias respecto a la posición de Gestido que no respaldaba la venta de publicidad comercial del SODRE. En este sentido, Vasconsellos aseguró que "Es propósito de nuestro sector político hacer todos los esfuerzos para lograr la unidad de acción del Partido Colorado, para obtener soluciones que permitan al país salir de esta situación difícil que atraviesa. En este esfuerzo no solo están comprometidos los legisladores: deben estar comprometidos también los integrantes del Poder Ejecutivo y esa manifestación individual que se manifiesta a través de cartas o declaraciones que comprometen orientaciones ideológicas de todo el Partido, sin que sean fruto de un cambio de opiniones previo en la órbita natural en que deben moverse los gobernantes, no es el camino más indi[cad]o [sic] para obtener esta colaboración"(DSCS, 13 de junio de 1967, t.258, p. 187). En contraposición, Cigliutti defendió la actuación del presidente, asegurando que consideraba la opinión del parlamento y atendía a la unidad del Partido. 
los principios legislados en su creación. Desde esta perspectiva, el senador batllista Luis Tróccoli afirmó:

"El SODRE está enfrentando una situación donde prácticamente deberá paralizar sus servicios, en aspectos vitales de su actividad si la ley no se cumple, y, como la ley no se cumple, puede verse obligado a adoptar actitudes y conductas que están reñidas con el espíritu que determinó su creación y al que, seguramente, todos aspiramos”69.

De igual forma, el senador Amilcar Vasconsellos -Partido Colorado, Por defensa del Batllismo- recordó el incumplimiento de la deposición legal que obligaba a los entes a destinar parte de su inversión en publicidad a la radio y televisión pública, lo que implicó que "el SODRE o tenía que seguir vegetando o tenía que buscar los caminos para vigorizar su propio trabajo y expandirse y se utilizó el camino de la propaganda comercial privada" 70 .

De Torres sostiene que la política cultural que adoptó el SODRE y llevó a cabo a través de su radio pública, estuvo influenciada por el modelo de la British Broadcasting Company (BBC), en tanto había una "reivindicación del rol del Estado no solo como regulador sino como productor de contenidos a través de una emisora propia”, no tenía publicidad sino que era mantenida con recursos públicos que permitían llevar a cabo una programación cuyo criterio fundamental estaba ligado a "la calidad" y la "alta cultura" 71 . En los inicios de la televisión pública podría verse una continuidad de esta influencia ${ }^{72}$. De Torres propone que la mirada hacia el modelo de la $\mathrm{BBC}$ cobró pregnancia en la tradición batllista uruguaya vigente en los años treinta. Sin embargo, hacia la década de los sesenta, la "crisis estructural" que

\footnotetext{
69 DSCS, 8 de mayo de 1966, t.252, p. 345.

70 DSCS, 13 de junio de 1967,t.258, p. 135

${ }_{71}$ DE TORRES, Inés, ob. cit., p. 136.

72 Recordemos en este sentido que el proyecto presentado por el SODRE en 1957 incluía un gravamen sobre los receptores domésticos, siguiendo el sistema de licencias británico. Además, en 1952 el Consejo Británico invitó el Director técnico del SODRE, Dante Tartaglia, a formarse y visitar las instalaciones de radio y televisión de la BBC (Expediente caratulado "Sodre. Anuncia que el Consejo Británico ha invitado al Director Técnico del Instituto a concurrir a Gran Bretaña para visitar las instalaciones de radio y televisión de la BBC. Se le expiden al Sr Tartaglia los resguardos del caso para el cumplimiento de su misión", Carpeta ${ }^{\circ}$ 0113, Caja 630, AGN) y, antes, en 1947, Justino Zavala Muniz había viajado a la BBC y "vino entusiasmado con la televisión inglesa, hizo una exposición en el Senado planteando la necesidad de que Uruguay tuviera televisión" (ZAVALA CARVALHO, Justino, entrevista de Carmen Estrugo, [inédita], 24 de octubre de 1995), lo que motivó en 1950 la autorización a la primera partida económica para dar inicio a la instalación de la televisión pública. Finalmente, la programación de la televisión del SODRE en su inicio estaba definida por los ejes informativo, educacional, artístico y cultural (Informe presentando ante el Director General del SODRE, Héctor Laborde, 21 de febrero de 1963, AJZC) y recién en 1967 incorpora el entretenimiento (Informe general del canal, 1967, AJZC).
} 
vivió el país -en los términos de Caetano y Rilla-, pusieron en juego, entre otros aspectos, el quiebre del modelo batllista73. En este marco, el discurso de los parlamentarios batllistas en 1966 y 1967 podría pensarse como un resabio de un rasgo estructural típico del Uruguay precedente, del orden de la "larga duración", que implicaba una concepción estatista fuerte. Así, el senador Luis Hierro Gambardella Partido Colorado, Batllismo, Unidad y Reforma- sostenía:

\begin{abstract}
"nosotros, si tuviéramos que optar entre uno y otro concepto de la filosofía de los fines del estado, optaríamos, tanto por convicción filosófica o jurídica, como por sentimiento de defensa de la nacionalidad, por el monopolio a cargo del Estado. Optaríamos por él por razones jurídicas, filosóficas y culturales porque en la médula misma de la filosofía de nuestro partido político, señor Presidente, está este concepto de que el Estado tienen capacidad, sin atentar contra las libertades fundamentales del hombre y del individuo, para establecer monopolios"74.
\end{abstract}

Sin embargo, en los tiempos que surgió la televisión pública, el modelo de la BBC era una imagen difícil de materializar con políticas comunicacionales concretas en Uruguay. Para Williams uno de los factores que explicaba el desarrollo de la BBC era el establecimiento de "una versión dominante de la cultura nacional en una clase dirigente inusualmente compacta, de manera tal que el servicio público podía entenderse y administrarse efectivamente como un servicio en armonía con los valores de una definición pública existente"75. Sin embargo, el Uruguay de la década de los sesenta estaba lejos de esta fraternidad política. La desestabilización a la interna de los dos partidos tradicionales que hemos mencionado da cuenta de la búsqueda por encontrar respuestas a la crisis estructural que vivía el país, lo que implicaba un debate sobre el "nuevo proyecto nacional"76. Lejos de una respuesta unánime, los actores políticos y sociales buscaron caminos diversos ya sea conformando nuevas agrupaciones a la interna de los partidos -o mutando en sus posiciones ideológicas-, reforzando los grupos políticos de izquierda y las

\footnotetext{
73 CAETANO, Gerardo; RILLA, José, ob. cit.

74 HIERRO GAMBARDELla, Luis. Sodre. Su derecho a publicidad. Su misión Educacional. La defensa de la soberanía. Montevideo, publicado por la Agrupación Batllista José E. Cámera, 1967, pp. 8-9. Algunos argumentos esgrimidos por el Herrerismo atacaron la autorización para la venta de publicidad comercial del SODRE recuperando también este componente tradicional que encontramos en el discurso batllista. En este sentido, el senador Herrerista José Pedro Bruno criticó la nueva normativa en tanto era un ejemplo de "la eterna historia de los entes autónomos que están liquidando al comercio y que van a terminar por liquidar a la República" (DSCS, 21 de junio de 1966,t. 254,p. 263). 75 WILLIAMS, Raymond, Televisión...., ob. cit., p. 49.

${ }^{76}$ CAETANO, Gerardo; RILLA, José, ob. cit., p. 216.
} 
agrupaciones de derecha, creando la Convención Nacional de Trabajadores u optando por la guerrilla urbana -sobre todo el Movimiento de Liberación Nacional Tupamaros (MLN)-, entre otras respuestas divergentes de la época. Como sostiene Caetano y Rilla -citando a Germán Rama-, la crisis del Uruguay de los sesenta "era también la de un modelo de "hiperintegración social" que había apostado a la sacralización de instituciones y valores sociales cuyo supremo objetivo era la obtención del consenso y la afirmación de un complejo sistema de garantías y seguridades recíprocas" 77

Las diferentes respuestas sociales a la crisis del país estuvieron influenciadas por el contexto internacional de la época y el debate sobre la televisión pública no fue ajeno a este rasgo general. Da cuenta de esto, una de las críticas que esgrimió ANDEBU al modelo de comunicación definido por el batllismo:

\footnotetext{
"la tendencia en Europa es hacia la consolidación del régimen monopólico estatal en los países sometidos a sistemas controlados por la Unión Soviética, y hacia la ampliación progresiva de la actividad privada en todos los demás. Se advierte claramente que en los países comunistas o procomunistas el concepto es que la radiodifusión debe estar férreamente controlada por el Estado, el cual se reserva su operación en exclusividad (...) En cambio, hay participación, predominio o exclusividad de la radiodifusión privada en los países prodemocráticos o de tradición liberal”78.
}

El ataque al discurso batllista sobre la televisión pública en el marco de la Guerra Fría, se resignificó como una prédica contra del comunismo en tanto el modelo de comunicación monopólico estaba directamente asociado al Régimen Soviético. Desde el comienzo de la Guerra Fría, la adhesión uruguaya a la esfera estadounidense estuvo acompañada del fortalecimiento del discurso anticomunista en distintos ámbitos sociales y políticos, recrudecido durante los años sesenta79 en el

\footnotetext{
77 CAETANO, Gerardo; RILLA, José, ob. cit., p. 218.

78 ANDEBU, ob. cit., p. 12.

79 BROQUETAS, Magdalena, "Los frentes del anticomunismo. Las derechas en el Uruguay de los tempranos sesenta", Contemporánea, año 3, vol. 3, 2012, pp. 11-29. No podemos afirmar aquí que el discurso anticomunista de ANDEBU sea otro aspecto de vinculación con el Herrerismo ni, tampoco, que su ataque implique directamente una asociación entre el Batllismo y el comunismo. El discurso anticomunista puede rastrarse hasta 1926, cuando Uruguay estableció lazos diplomáticos con la URSS (APARICIO, Fernando y otros, Espionaje y política, Montevideo, Ediciones B, 2013) y permeó a gobiernos colorados y blancos (FREGA, Ana, ob. cit.). Por lo demás, las relaciones de los sectores políticos con los Estados Unidos (ALDRIGHI, Clara, "El discreto encanto de la tutela norteamericana. Políticos uruguayos y amenazas de golpe de Estado (1954- 1966)", Huellas de Estados Unidos. Estudios y debates sobre América Latina, 2012, pp. 80- 90; APARICIO, Fernando y otros, Espionaje y política, Montevideo, Ediciones B, 2013) y su vínculo con los discursos anticomunistas de los años sesenta son demasiado complejos y oscilantes como para abordarlos aquí. Nos limitamos a observar la
} 
contexto general de la crisis de integración social. De esta forma, el debate sobre la venta de publicidad comercial del SODRE llevó a una discusión más amplia sobre la política comunicacional que debía adoptar el Estado uruguayo. En este sentido más general, las respuestas que buscaron los distintos grupos políticos y empresariales parecen imbricarse en un debate social más amplio sobre la salida a la crisis del país donde se conjugaban las tradiciones y coyunturas locales con el marco general mundial.

\section{La televisión educativa: entre la tradición del SODRE y la política norteamericana}

Hasta ahora parecen delinearse dos perspectivas sobre la venta de publicidad comercial y el modelo de comunicación que debía definir el país: por un lado, el Batllismo y su prédica por un modelo estatista -ligado al proyecto de la BBC- y, por otro, el Herrerismo y ANDEBU en la reivindicación de un modelo más liberal ligado a la tendencia norteamericana. Sin embargo, esta partición no es tan simple, como puede observarse respecto a otro de los temas abordados en la discusión sobre la venta de publicidad comercial del SODRE: sus funciones institucionales. En el debate parlamentario, se argüía a favor y en contra sobre el impacto que tendría este mecanismo en el cumplimiento de las finalidades del SODRE. Sus objetivos de difundir programación cultural e informativa estuvieron vinculados a una concepción pedagógica de sus medios de comunicación, ligados a la idea de "alta cultura". En general, los parlamentarios y ANDEBU coincidían en el carácter educativo que debía perseguir la televisión pública. Desde el Partido Nacional, Eduardo Víctor Haedo (LA de Herrrera) aseguró: "Siempre entendimos y creo que siempre se entendió que iba a ser un Instituto [el SODRE] que implicaría gastos al Estado pero que debía ser mantenido realizando función estrictamente docente" ${ }^{80}$. De igual forma, Hierro Gambardella sostuvo: "hay una misión que es absolutamente irrenunciable, de la

forma en que ANDEBU relacionó el modelo de comunicación que definía el Batllismo en este debate con el comunismo. La referencia que hizo la Asociación en sus publicaciones a la posición de Hierro Gambardella es particularmente interesante en tanto el senador había pertenecido a la lista 15 -para las elecciones de 1966 integró el lema Unidad y Reforma-, tachada por varios sectores sociales y políticos -sobre todo desde el ruralismo de Nardone- como comunista. (ALONSO ELOY, Rosa; DEMASI, Carlos, ob. cit.; BROQUETAS, Magdalena, ob. cit.,).

Por otra parte, es interesante notar que la influencia extranjera en los medios de comunicación locales y en el marco de la Guerra Fría tenía como antecedente la exhibición de la película "La Cortina de Hierro" en el Cine Trocadero, aunque se trató de un suceso muy diferente al que aquí analizamos (APARICIO, Fernando y otros, ob. cit., pp. 51- 73).

8o DSCS, 21 de junio de 1966, t., 254, p. 261. 
naturaleza jurídica, espiritual y cultural del canal oficial. Esa misión, además, está teniendo una trascendencia creciente. Es la misión educacional" 81

En efecto, Zavala defendió la actividad educativa de la televisión pública como uno de sus ejes principales -junto a la artística, informativa y, posteriormente, el entretenimiento-82. Para desarrollar este objetivo Zavala propuso dos líneas de trabajo. En primer lugar, elaboró una propuesta de programación orientada hacia los distintos niveles de educación formal y en trabajo conjunto con sus respectivas instituciones - primaria, secundaria, Universidad del Trabajo y Universidad de la República-. En segundo lugar, buscó desarrollar los tele- clubes, es decir, programas que serían recepcionados en forma colectiva por determinados grupos sociales cuyos contenidos eran creados especialmente para sus preocupaciones y necesidades. La aspiración a consolidar una televisión educativa impregnó los programas de enseñanza y el desarrollo de las televisoras públicas en la región. Tal y como señala Fuenzalida,

"en América Latina, el esfuerzo por introducir TV pública escolar correspondía a un diagnóstico de agencias especializadas para enfrentar la deficiente escolaridad formal y de organismos internacionales de ayuda al desarrollo, las cuales había concluido aproximadamente entre los años 1960 y 1975- que los mayores esfuerzos conducentes a la mejoría de la calidad de la escuela no debían focalizarse tanto en los procesos intrescolares de enseñanza- aprendizaje, sino a una intervención tecnológica externa mediante la televisión pública educativa”. ${ }^{83}$

Enmarcado en este modelo, Zavala participó en un seminario de televisión educativa realizado entre el 4 de junio y el 8 julio de 1964 impulsado por la Organización de Naciones Unidas para la Educación, la Ciencia y la Cultura (UNESCO) - a través de su entonces secretario general, Jaime Torres Bodet- y el gobierno de México. De igual forma, hacia 1966 el programa de tele- clubes despertó el interés de la UNESCO y la organización Peace Corps de Estados Unidos. Hubo una visita de la UNESCO al canal para discutir vías de apoyo a la televisión educativa y la Peace Corps se comunicó con la televisora para colaborar con su proyecto educativo y -sobre todo- con los tele-clubes.

81 HIERRO GAMBARDELLA, Luis, ob. cit., p. 16.

82 Informe presentando ante el Director General del SODRE, Héctor Laborde, 21 de febrero de 1963, AJZC; Informe general del canal, 1967, AJZC.

83 FUENZALIDA, Valerio, "Programación: por una televisión pública en América Latina”, en RINCÓN, Omar (comp.) Televisión pública: del consumidor al ciudadano, Buenos Aires, La Crujía, 2005, p. 142. 
Hacia los sesenta, UNESCO desarrolló una política de trabajo en relación a la comunicación en América Latina a partir de diversos ejes que preocupaban a la institución ${ }^{84}$, entre las cuales se destacó la búsqueda por la democratización educativa, suponiendo "que los medios o vehículos electrónicos (radio y televisión) posibilitarán la alfabetización en masa, la educación continuada de las minorías poblacionales, a bajo costo" 85 . Durante los sesenta, la doctrina promovida por la UNESCO y la CIESPAL estuvo influenciada por el funcionalismo norteamericano y la teoría desarrollista, con lo cual, se sostenía que el desarrollo latinoamericano estaba ligado a la difusión del conocimiento norteamericano y sus medios de comunicación $^{86}$. Por ejemplo, Schramm -uno de los expertos consultores de la UNESCO- aseguraba que el crecimiento de la cantidad de medios de comunicación se relacionaba con el progreso económico y social. Los medios debían usarse para contribuir al sentimiento de nación, expandir conocimiento -sobre todo difundir el alfabetismo-, "preparar a la gente" para el papel que les depara el futuro desarrollo y fomentar el vínculo entre las naciones, entre otras funciones. Desde una perspectiva liberal, el fomento a la empresa privada implicaba que "se alentará la propiedad privada de los medios de comunicación, y la publicidad tendrá la oportunidad de desempeñar un importante papel en la expansión de los mercados. En este campo también los países en desarrollo tienen mucho que aprender de los más adelantados" 87 .

Por lo tanto, no parece posible ligar claramente las posiciones políticas con la influencia de modelos de comunicación extranjera. Lo local y lo foráneo se imbricaron en diálogos más complejos, de lo que aquí apenas podemos dar cuenta.

\footnotetext{
84 Por ejemplo, los usos del cine, la investigación sobre políticas de comunicación, la profesionalización del trabajo periodístico, el vínculo entre los medios de comunicación y el sector rural o la relación de los medios masivos con la educación (MORAGAS, Miquel de, Teorías de la comunicación. Investigaciones sobre medios en América y Europa, México, Gustavo Gili, 1991).

85 MARQUÉS DE MELO, José, "Teoría e investigación de la comunicación en América Latina. Balance preliminar de los últimos 25 años", Estudios sobre las culturas contemporáneas, año/vol. 1, $\mathrm{n}^{\circ}$ 2, Universidad de Colima, p. 55. En el marco de esta política, se promovió que los países latinoamericanos importaran tecnologías y formaran recursos humanos para su manejo. Al mismo tiempo, se impulsó la formación de profesionales, el desarrollo de centros especializados en la formación de comunicadores y el fomento a la investigación en comunicación a través del Centro Internacional de Estudios Superiores de Comunicación para América Latina (CIESPAL).

86 Esta tradición fue cuestionada fuertemente sobre todo a partir del encuentro de investigadores latinoamericanos de comunicación promovido por la CIESPAL en 1973 en Costa Rica.

${ }_{87}$ SCHRAMM, Wilbur "El desarrollo de las comunicaciones y el proceso de desarrollo", en PYE, Lucian W. (comp.) Evolución política y comunicación de masas. Buenos Aires, Troquel, 1969. Disponible en Internet: http://www.infoamerica.org/documentos_pdf/schramm_01.pdf. (Consultado el 19 de setiembre de 2016), p. 8.
} 
Sin embargo, la defensa de la televisión educativa puede ayudar a comprender cómo operaba, en diferentes niveles, la influencia foránea -en este caso, la norteamericanasobre la definición de las políticas pública en comunicación que debía seguir el Estado.

Después de dos años de debates en la Cámara de Diputados y, sobre todo, en la de Senadores, una extensa exposición del senador Hierro Gambardella realizada el 16 de agosto de 1967 en defensa del SODRE y su derecho a la venta de publicidad comercial, fue votada unánimemente. Hacia el final de esa sesión el senador Carlos Julio Pereyra (Partido Nacional, Reforma y Desarrollo) aclaró: "como integrantes de nuestro sector no hicieron uso de la palabra en este debate, nuestro voto afirmativo tienen el significado de solidaridad con el planteamiento realizado y el propósito de defender al SODRE" 88 . Sin embargo, García Rubio ${ }^{89}$ constata que en junio de ese mismo año renunció toda la Comisión Directiva del SODRE por entender que no contaban con el respaldo del Poder Ejecutivo -presidido por Oscar Gestido- en el conflicto con ANDEBU.

En enero de 1968 el Canal 5 fue intervenido por el presidente Jorge Pacheco Areco, pero una semana antes Zavala no pudo ingresar al Canal 5, fue separado de su cargo y se le inició un sumario por presuntas irregularidades en la contratación de cantante Charles Aznavour, disputado por todos los medios locales ${ }^{90}$. En mayo de ese mismo año, se contrató como director general a Rubén Rodríguez, gerente comercial del Canal 12. Con él llegaron trabajadores de otros medios que ayudaron a desdibujar el perfil del proyecto de la televisora estatal y relegaron de sus tareas a los funcionarios antecesores. A pesar de la posición final que acordó el Parlamento respecto al rumbo, funciones, institucionalidad y forma de financiación de la televisión pública, el Poder Ejecutivo -cada vez más fortalecido en sus funciones en los años previos a la Dictadura- intervino en concordancia con los reclamos empresariales, en cuyas manos se dejó el rumbo del canal estatal.

\footnotetext{
88 HIERRO GAMBARDELLA, Luis, ob. cit., p. 49.

89 GARCÍA RUBIO, Carlos, (ed.), Televisión estatal...ob., cit.

$9^{\circ}$ Las causas para la apertura de un sumario y la separación del cargo de Justino Zavala Carvalho de deben a la contratación del cantante Charles Aznavour en mayo de 1966, es decir, en el marco de la controversia por la venta de publicidad comercial por parte de los medios de comunicación del SODRE. El confuso conflicto emerge a partir de un enfrentamiento con el productor Marcos Ohanessián encargado de hacer las negociaciones con el cantante para su presentación en el SODRE y responsable del programa "Armenia en el Uruguay".
} 


\section{Consideraciones finales}

Hemos intentado mostrar algunas características de la reglamentación e implementación que enmarcó y permitió el nacimiento de la televisión pública en Uruguay. El carácter técnico de la normativa que rigió el ejercicio de la radio y la televisión, parece manifestar una línea de continuidad entre ambos medios que da cuenta de una concepción aún ligada al "televisor" y no a la "televisión". La inscripción del nuevo medio público en el SODRE lo vinculan a sus funciones institucionales y al proyecto cultural. Pero en un marco regulatorio que establecía una política comunicacional ambigua y difusa, el efectivo cumplimiento de estos objetivos pareció no poder concretarse y cuando los intereses de las empresas comerciales se vieron afectados por el ejercicio del Canal 5, se lanzaron en una fuerte batalla reivindicando sus "derechos".

Aunque la regulación sobre los medios de comunicación no tuvo grandes variaciones hasta la Dictadura91, las propuestas que buscaron crear una televisión alternativa y las diferentes posiciones en el debate parlamentario de 1966 y 1967, muestran la complejidad de un proceso que no se reduce a lo que efectivamente fue la televisión pública en los sesenta. En este sentido, buscamos comprender cómo la discusión sobre una medida concreta - la autorización a vender publicidad comercial de la televisión pública- motivó reflexiones más amplias sobre la política comunicacional del país. En este marco más general, las diferencias entre los partidos políticos y las empresas comerciales de televisión parecen estar imbricadas en la crisis estructural de los años sesenta. El resquebrajamiento del modelo batllista y la búsqueda por dar respuestas al "nuevo proyecto país" intervienen en las líneas argumentativas que defienden o rechazan los actores políticos y empresariales. También se juegan en ellas la influencia de los tradicionales modelos de comunicación norteamericanos y británicos que, interpretados localmente en el marco de la Guerra Fría, cobran diferentes significaciones.

En tanto presentamos aquí algunos avances de una investigación aún en curso, el artículo pretender abrir interrogantes más que llegar a conclusiones certeras. Si efectivamente es posible analizar el período de los sesenta como un momento de

${ }_{91}$ MARCHESI, Aldo, El Uruguay inventado: La política audiovisual de la dictadura, reflexiones sobre su imaginario, Montevideo, Trilce, 2001. 
discusión sobre las políticas públicas que debía llevar adelante el Estado en materia de comunicación y -particularmente- en relación a la televisión pública, resulta pertinente analizar las distintas concepciones de los actores políticos y sociales que dialogaron en la definición de la televisión como institución social. Este proceso parece poner en juego diferentes formas de entender la comunicación y su vínculo con la sociedad. El desafío abierto es intentar trazar este complejo mapa en el contexto de influencias extranjeras -como modelos a seguir o injerencias concretas- $y$ una coyuntura local en crisis que busca (re)pensarse como país.

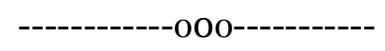

\section{Bibliografía}

ALDRIGHI, Clara, "El discreto encanto de la tutela norteamericana. Políticos uruguayos y amenazas de golpe de Estado (1954- 1966)", Huellas de Estados Unidos. Estudios y debates sobre América Latina, ${ }^{\circ}$ 2, 2012, pp. 80- 90.

ALONSO ELOY, Rosa; DEMASI, Carlos, Uruguay 1958- 1968. Crisis e estancamiento, Montevideo, Banda Oriental, 1986.

APARICIO, Fernando y otros, Espionaje y política, Montevideo, Ediciones B, 2013.

BECEIRO, Ildefonso, La radio y la TV de los pioneros, Montevideo, Banda Oriental, 1994.

BROQUETAS, Magdalena, "Los frentes del anticomunismo. Las derechas en el Uruguay de los tempranos sesenta”, Contemporánea, año 3, vol. 3, 2012, pp. 11-29.

CAETANO, Gerardo; RILLA, José, Historia contemporánea del Uruguay. De la colonia al Mercosur, Montevideo, Fin de siglo, 1995.

DE TORRES, Inés, "El surgimiento de la radiodifusión pública en Hispanoamérica. Contextos, modelos y el estudio de un caso singular: el SODRE, la radio pública estatal de Uruguay (1929)", Revista internacional de Historia de la Comunicación, $\mathrm{n}^{0}$ 5, vol.1, 2015, pp. 122-142.

FARAONE, Roque, Televisión y Estado, Montevideo, Cal y Canto, 1998. 
FARAONE, Roque, Estado y T.V. en el Uruguay, Montevideo, Fundación de Cultura Universitaria, 1989.

FARAONE, Roque, Medios masivos de comunicación, Montevideo, Colección Nuestra Tierra, 1969.

FREEDMAN, Des, "Las dinámicas del poder en la elaboración de políticas de medios en la actualidad", Media, Culture \& Society, v. 26, no 6, noviembre 2006, Londres. [Traducción realizada por el equipo de cátedra de "Políticas y planificación de la comunicación”, de la Facultad de Ciencias Sociales, UBA] Disponible en: http://politicasyplanificacion.sociales.uba.ar/files/2014/07/freedman.pdf (Consultado el 20 de abril de 2016).

FREGA, Ana y otros, Historia del Uruguay en el siglo XX (1890-2005), Montevideo, Banda Oriental, 2010.

FUENZALIDA, Valerio, "Programación: por una televisión pública en América Latina”, en RINCÓN, Omar (comp.) Televisión pública: del consumidor al ciudadano, Buenos Aires, La Crujía, 2005.

GARCÍA RUBIO, Carlos (ed.), Televisión estatal ¿qué hacer con ella?, Montevideo, Universidad Católica del Uruguay, 1998.

HALL, Stuart, “Codificación y decodificación del discurso televisivo”, Cuadernos de Información y Comunicación, $\mathrm{n}^{\circ}$ 9, 2004, pp. 210- 236.

MARCHESI, Aldo, El Uruguay inventado: La política audiovisual de la dictadura, reflexiones sobre su imaginario, Montevideo, Trilce, 2001.

MARONNA, Mónica, La radio en busca de oyentes. Historia social y cultural de la radiofonía en Montevideo (1922- 1939), [tesis de Doctorado inédita], Buenos Aires, 2016.

MARONNA, Mónica, “La radio montevideana en busca de oyentes”, Cuadernos del Claeh, año 33, nº 100 ( $2^{\mathrm{a}}$ serie), 2012, pp. 149-172.

MARQUÉS DE MELO, José, “Teoría e investigación de la comunicación en América Latina. Balance preliminar de los últimos 25 años”, Estudios sobre las culturas contemporáneas, año/vol. 1, $\mathrm{n}^{\circ}$ 2, Universidad de Colima, p. 55.

MASTRINI, Guillermo (ed.), Mucho ruido, pocas leyes. Economía y políticas de comunicación en la Argentina, Buenos Aires, La crujía, 2009. 
MATTOS, Sergio, "Un perfil de la televisión brasilera: 40 años de historia (19501990)", Comunicación y Sociedad, $\mathrm{n}^{0}$ 16- 17, setiembre - abril, 1993, Universidad de Guadalajara, pp. 45- 74.

MORAGAS, Miquel de, Teorías de la comunicación. Investigaciones sobre medios en América y Europa, México, Gustavo Gili, 1991.

PEREIRA, Antonio, "Televisión y Dictadura en el Uruguay: cambios y permanencias", en ReHiMe. Cuadernos de la Red de Historia de los Medios, Prometeo, Buenos Aires, 2012, pp. 140-179.

PRATS, Luis, Ayer te vi. Crónica de la televisión uruguaya, Montevideo, Ediciones de la Banda Oriental, 2009.

SCHRAMM, Wilbur "El desarrollo de las comunicaciones y el proceso de desarrollo", en PYE, Lucian W. (comp.) Evolución política y comunicación de masas. Buenos Aires, Troquel, 1969. Disponible en: http://www.infoamerica.org/documentos pdf/schramm 01.pdf (Consultado el 19 de setiembre de 2016)

VAN CUILENBURG, Jan; MCQUAIL, Denis, "Cambios en el Paradigma de Política de Medios. Hacia un nuevo paradigma de políticas de comunicación”, European Journal of Communication, vol 18, $\mathrm{n}^{0}$ 2, Sage, Londres, pp. 181-207. [Traducción a cargo del equipo conformado por Mariela Baladrón, Ana Bizberge, Marianela Del Giúdice, Cecilia Fariña, Jorgelina Rojo, Magdalena Restovich, Bernadette Califano y Guillermo Mastrini. Disponible en: http://mbecerra.blog.unq.edu.ar/modules/docmanager/index.php?curent di $\underline{r}=12$ (Consultado el 20 de abril de 2016)].

VARELA, Mirta, "Televisión pública en América Latina: instrumento político, experimento estético, audiencia nacional”, en GUÉRIN, Ana Isabel y otros (comp.), Pensar la televisión pública, Buenos Aires, La Crujía, 2013.

VARELA, Mirta, La televisión criolla, Buenos Aires, Edhasa, 2005.

VARELA, Mirta, "Del televisor a la televisión: La incorporación de la TV en la Argentina”, Causas y Azares. Los lenguajes de la comunicación y la cultura en (la) crisis. Buenos Aires, año III, ${ }^{\circ}$ 4, 1996, pp. 107-115.

WILLIAMS, Raymond, Televisión. Tecnología y forma cultural, Buenos Aires, Paidós, 2011.

WILLIAMS, Raymond, La larga revolución, Buenos Aires, Nueva Visión, 2009. WILLIAMS, Raymond, Marxismo y literatura, Barcelona, Península, 2000. 


\section{Fuentes}

Archivo personal de Justino Zavala Carvalho.

ANDEBU, Memorandum 67, Montevideo, ANDEBU, 1967, Uruguay.

ANDEBU, Una ofensiva contra la radio y la televisión, 1963, Uruguay

ASAMBLEA GENERAL, Diario de sesiones, 1950- 1966, Uruguay.

CÁMARA DE SENADORES, Diario de sesiones, 1963-1968, Uruguay.

CÁMARA DE REPRESENTANTES, Diario de sesiones, 1963-1968, Uruguay.

Fondo del Ministerio de Instrucción Pública y Previsión Social, Archivo General de la Nación, Uruguay.

HIERRO GAMBARDELLA, Luis, Sodre. Su derecho a publicidad. Su misión Educacional. La defensa de la soberanía. Montevideo, publicado por la Agrupación Batllista José E. Cámera, 1967.

MINISTERIO DE DEFENSA, Normas provisorias jurídico administrativas para la explotación de estaciones de televisión, Montevideo, Imprenta militar, 1956.

SERVICIO OFICIAL DE DIFUSIÓN RADIO ELÉCTRICA, Su organización y cometidos. Memoria de la labor realizada entre 1930-1962, Montevideo, SODRE, 1936.

URUGUAY. Registro Nacional Leyes y Decretos (RNLyD). Años: 1928, 1936, 1944, 1945, 1964, 1965 .

ZAVALA CARVALHO, Justino, entrevista de Carmen Estrugo, [inédita], 24 de octubre de 1995 . 